Article

\title{
On Setting Day-Ahead Equity Trading Risk Limits: VaR Prediction at Market Close or Open?
}

\author{
Ana-Maria Fuertes ${ }^{1, *,+}$ and Jose Olmo ${ }^{2}$ \\ 1 Faculty of Finance, Cass Business School, City University London, 106 Bunhill Row, London EC1Y 8TZ, UK \\ 2 University of Southampton, Highfield Campus, Southampton SO17 1BJ, UK; J.B.olmo@soton.ac.uk \\ * Correspondence: a.fuertes@city.ac.uk; Tel.: +44-020-7040-0186 \\ + These authors contributed equally to this work.
}

Academic Editors: Stefan Mittnik and Marc S. Paolella

Received: 4 July 2016; Accepted: 23 August 2016; Published: 9 September 2016

\begin{abstract}
This paper investigates the information content of the ex post overnight return for one-day-ahead equity Value-at-Risk (VaR) forecasting. To do so, we deploy a univariate VaR modeling approach that constructs the forecast at market open and, accordingly, exploits the available overnight close-to-open price variation. The benchmark is the bivariate VaR modeling approach proposed by Ahoniemi et al. that constructs the forecast at the market close instead and, accordingly, it models separately the daytime and overnight return processes and their covariance. For a small cap portfolio, the bivariate VaR approach affords superior predictive ability than the ex post overnight VaR approach whereas for a large cap portfolio the results are reversed. The contrast indicates that price discovery at the market open is less efficient for small capitalization, thinly traded stocks.
\end{abstract}

Keywords: overnight information; price discovery; realized VaR; realized volatility; Value-at-Risk

JEL Classifications: C52; C53; G15

\section{Introduction}

Existing market microstructure research documents that the flow of information is greater during trading (daytime) hours than during non-trading (overnight) hours. ${ }^{1}$ However, with the increasing globalization of securities markets and electronic trading systems such as electronic communication networks (ECNs), the importance of the overnight information flow will increase since events from around the globe can trigger investor reactions in all markets. ${ }^{2}$ In principle, the events that occur during overnight non-trading hours will typically be impounded into prices very rapidly when an exchange opens for a new trading day. Assuming an absence of trading during the overnight period, we address the question of how to tackle the overnight segment of the day for daily Value-at-Risk (VaR) forecasting. VaR has become the standard tail risk management tool for setting day-by-day loss limits of equity trading desks in commercial banks. Through one-day-ahead VaR forecasting, the bank's risk management team routinely estimates the equity portfolio tail risk exposure seeking to ensure that the equity trading desk stays within predefined risk limits.

In order to assess the information content of the ex post observed overnight price variation for VaR forecasting, we will compare two modeling approaches. One is the bivariate approach proposed by Ahoniemi et al. [5] which applies to a setup where forecaster constructs the day-ahead prediction

1 See George and Hwang [1], Jones et al. [2], and French and Roll [3], inter alios.

2 De Goojier et al. [4] exploit full information in the intra-day stock price patterns in foreign markets during non-trading hours in a home market to predict the opening of an index in the home market. 
for day $t$ at the close of day $t-1$ when the day $t$ overnight segment is not observed yet and hence, cannot be part of the conditioning information set. This bivariate framework is rather flexible not only because it allows for different data generating processes for the overnight and daytime segments of the $24 \mathrm{~h}$ day period but also because it accommodates the potentially non-zero ex-ante covariance term (due to inefficiencies in the price discovery process at the market open) between the returns on both segments. During the overnight period, equity markets are closed for trading, although the news releases do not cease. Once markets open for trading, market microstructure effects such as price staleness and news spillover can induce a non-zero covariance between daytime and overnight returns that may be valuable in setting the day $t$ equity VaR limits at the close of day $t-1$. After the market opens, it takes some time before all stocks begin trading. Thus, the first published stock index quotes of each day will contain numerous stale prices, i.e., transaction prices from the previous day and hence, the overnight (close-to-open) return can be highly noisy. ${ }^{3}$ The fact that the first index quotes are stale means that their values do not fully reflect all overnight news. Thus, overnight information can spill further into the trading day, inducing a non-zero covariance between the ex ante intraday and overnight innovations.

The second VaR modeling approach applies to a forecaster who chooses to construct the day-ahead prediction for day $t$ at the market open and hence, she is able to exploit a larger information set that also contains the ex post observed overnight price variation. The key question is how informative this ex post observed overnight price variation is and, equivalently, whether this approach generates more accurate VaR forecasts than the bivariate approach that instead forecasts the overnight price variation. As motivated above, the rationale for the comparison of the bivariate VaR modeling framework and the ex post overnight VaR modeling framework is to determine the influence of price staleness in opening market prices, assess the biases of VaR forecasts produced by these market imperfections and measure the extent of news spillovers in market risk measures. The empirical analysis relies on high-frequency data for two equity markets with different degrees of liquidity and trading volume.

The two aforementioned day-ahead $\mathrm{VaR}$ forecasting frameworks are evaluated using different statistical methods. First, we employ the unconditional predictive ability test proposed in Giacomini and White [11]. This test builds on the suitable "tick" or "check" loss function of quantile regression theory. Second, we assess the criterion of correct conditional coverage of the $\alpha$-quantile (or VaR) forecasts through the Engle and Manganelli [12] dynamic quantile test and a probit-based version with improved statistical properties.

Overall the findings suggest that incorporating directly the ex post observed overnight price variation in the day-ahead VaR forecast has merit for the S\&P 500 portfolio but not for the Russell 2000 portfolio. Together with any practical difficulties that bank risk managers may find in trying to generate the day-ahead VaR forecasts at the market open-instead of at the previous-day market close as it is typical - the contrasting findings for the two indices suggest that risk managers should adopt the more conservative stance of relying on a bivariate model that forecasts both the overnight and daytime returns and their covariance, instead of conditioning their VaR forecast on the noisy close-to-open (overnight) return data gathered at the immediate start of the trading day.

The empirical evidence from our VaR forecasting analysis indirectly confirms the presence of inefficiencies in the opening price discovery process, particularly, for low trading-volume stocks. Barclay and Hendershott [13] show that the opening price conveys more fundamental information for high trading-volume stocks. Hasbrouck [14] provides evidence that the initial part of the trading

3 Stoll and Whaley [6] document empirically that it took around five to six minutes in the 1980s for large stocks to open for trading on the NYSE. Of course, with the advent of electronic trading platforms, the average time to open in today's markets is much shorter, but large cap stocks are still expected to open for trade faster than small cap stocks. Various empirical studies implicitly acknowledge this "delay"in price discovery. Ahoniemi and Lanne [7] and Chan et al. [8] both wait until $5 \mathrm{~min}$ of trading has elapsed before calculating an overnight return. Masulis and Shivakumar [9] waits 15 min, and Lin et al. [10] wait for a full $30 \mathrm{~min}$. 
day is characterized by very rapid bid-ask oscillations, particularly for small cap stocks, which are noisy and unlikely to reflect overnight news about fundamentals. The upshot is that small cap stocks are likely to exhibit less efficient opening prices. Our results are in line with this wisdom since clearly for the Russell 2000 index (but not for the S\&P 500 index) the bivariate VaR modeling approach that conditions on the information available at the close of day $t-1$ is more reliable for computing accurate one-day-ahead equity trading limits than the ex post overnight VaR that generates the forecast at the market open by incorporating the realized overnight return. The opening prices of the larger volume S\&P 500 constituents are more efficient, meaning that here it would be useful (were it feasible) for risk managers to wait to observe the overnight return before setting VaR limits for the day.

Forecasting approaches that are similar in spirit to the bivariate and ex post overnight frameworks here employed exist in the literature. In a bivariate modeling framework, Andersen et al. [15] characterize the daytime return variation as a long-memory HAR process, while the overnight return variation is portrayed as a GARCH type process. A noticeable difference between this bivariate VaR modeling approach and ours is that the former does not allow the overnight-intraday covariance to play a role. Moreover, the forecast target in Andersen et al. [15] is the volatility per se (not a quantile of the return distribution) and the forecast evaluation hinges on a proxy constructed as the sum of the squared close-to-open overnight return and the squared intraday high-frequency returns. Accordingly, using the Mincer-Zarnowitz $R^{2}$ criterion, they conclude that there are benefits to separately modeling the daytime and overnight volatility components. In a similar spirit to the univariate ex post overnight approach deployed in our paper, existing studies predict the day-ahead return variation through long-memory (ARFIMA) models fitted to a history of open-to-close realized volatilities constructed from intraday prices (e.g., Corsi et al. [16]; Thomakos and Wang [17]; Andersen et al. [18]). We proceed similarly but, in contrast, the ex post overnight approach deployed in our paper additionally exploits the close-to-open return that becomes available to the forecaster at market open.

Our empirical analysis is confined to equity indices but is potentially relevant to any market where trading ceases for certain periods - this still applies to the majority of securities markets worldwide, including the U.S. futures market which is closed to trading over weekends. There is a parallel, smaller empirical literature on daily volatility forecasting that focuses on futures (instead of cash) markets where trading also occurs overnight through specific electronic trading platforms. For instance, Taylor [19] models separately the per-hour returns from 12:00 am to 8:30 am (E-mini S\&P 500 futures), 8:30 am to 3:15 pm (regular S\&P 500 futures), and 3:15 pm to 12:00 am (E-mini S\&P 500 futures). Martens [20] uses intra-day and intra-night S\&P 500 futures prices observed at the $5 \mathrm{~min}$ and $15 \mathrm{~min}$ frequencies, respectively. However, despite the overnight trading platforms, not only price volatility and trading volume are highly concentrated during the 8:30-15:00 EST segment of the $24 \mathrm{~h}$ day but the U-shaped patterns of price volatility, trading volume, and the bid-ask spread observed during this segment resemble those found in equity markets. For this reason, some studies employing futures prices still focus on the main open outcry Chicago Merchantile Exchange (CME) trading hours like Giot and Laurent [21], Žikěs [22] and Fuertes and Olmo [23].

This study continues as follows. Section 2 presents the continuous-time price process underlying the bivariate model, its location-scale stationary representation, and two competing day-ahead return mean and variance forecasting methods that differ in how the overnight return of the forecasted day is conceptualized (ex ante unobserved at the previous day close or ex post observed at the market open). Section 3 sets out the VaR forecasts and evaluation methods. Section 4 discusses the empirical results before concluding in a final section.

\section{Overnight Information for Modeling Daily Prices}

This section begins by presenting a general framework for forecasting the day-ahead close-to-close return and variance. Sections 2.2 and 2.3 discuss, respectively, as particular and competing approaches, the forecasting equations of Ahoniemi et al. [5] that condition on information up to the market close, 
and the novel univariate modeling approach here entertained that conditions on information up to the market open which thus, incorporates the overnight close-to-open return.

\subsection{Overnight and Daytime Integrated Variance Processes}

The diffusion of the log-price process, assuming as it is usual in the finance literature that it belongs to the class of semimartingales, is described by the stochastic differential equation

$$
d p_{t}=\mu_{t} d t+\sigma_{t} d W_{t}+\kappa_{t} d q_{t}, \quad 0 \leq t \leq T
$$

where $\sigma_{t}$ is the instantaneous or spot volatility process which is stationary and independent of the random Brownian motion $W_{t}$, and $\mu_{t}$ the instantaneous deterministic drift term; $\kappa_{t} d q_{t}$ refers to the pure jump part, where $d q_{t}=1$ if there is a jump at time $t$ and 0 otherwise, where the jumps occur with potentially time-varying jump intensity $\lambda_{t}$, and size $\kappa_{t}$, see, for example, Andersen et al. [15] for a similar specification.

Let $O_{t}$ and $C_{t}$ represent the market opening and closing times of day $t$, respectively. The time period from $C_{t-1}$ to $C_{t}$ spans the entire $24 \mathrm{~h}$ day $t$ that can be split into the overnight period when the market is closed from $C_{t-1}$ to $O_{t}$, and the official daytime trading period from $O_{t}$ to $C_{t}$; likewise, the period from $C_{t}$ to $C_{t+1}$ spans the $24 \mathrm{~h}$ day $t+1$ and so forth. The day $t$ return is defined as $r_{t} \equiv p_{C_{t}}-p_{C_{t-1}}$ with lowercase $p$ denoting a logarithmic price measure. It follows from Equation (1) that the quadratic variation of the daily return process is given by

$$
Q V_{t}=I V_{t}+\sum_{C_{t-1} \leq s \leq C_{t}} \kappa_{s}^{2}
$$

with $I V_{t} \equiv V\left(r_{t}\right)=\int_{C_{t-1}}^{C_{t}} \sigma_{s}^{2} d s$ the integrated variance of the daily return process and $\sum_{C_{t-1} \leq s \leq C_{t}} \kappa_{s}^{2}$ denoting the aggregate contribution of discrete jumps to the daily quadratic variation process. The different dynamics of the overnight and daytime components of the continuous time log-price process can be accommodated by rewriting (1) as

$$
d p_{t}=\left\{\mu_{o, t} d t+\sigma_{o, t} d W_{o, t}\right\} 1\left(C_{t-1}<t \leq O_{t}\right)+\left\{\mu_{d, t} d t+\sigma_{d, t} d W_{d, t}+\kappa_{d, t} d q_{d, t}\right\} 1\left(O_{t}<t \leq C_{t}\right),
$$

where the deterministic sequences $\mu_{o, t}$ and $\mu_{d, t}$ are the spot overnight and daytime drifts, respectively, the random sequences $\sigma_{o, t}$ and $\sigma_{d, t}$ are the spot volatility processes, and $W_{o, t}$ and $W_{d, t}$ are the overnight and daytime Brownian motions. We include a jump component for the daytime segment, denoted as $\kappa_{d, t} d q_{d, t}$, and assume, for simplicity, the overnight return to follow a continuous diffusion process. This assumption is consistent with Hansen and Lunde [24], inter alios, that assume a negligible effect of jumps on the daily price diffusion. We should note that our model is richer than Hansen and Lunde [24] in the sense that it accommodates the presence of jumps in the daytime component of the daily return process.

For forecasting purposes, we define the conditioning information set or sigma-algebra $\Im_{t-1}$ that contains all the information available to the forecaster at time $C_{t-1}$. Conditional on this sigma-algebra, the Brownian motions in Equation (3) can be related, that is, $E\left[d W_{o, s} d W_{d, s^{*}} \mid \Im_{t-1}\right]=\rho_{s s^{*}}$ where $C_{t-1}<s<O_{t}<s^{*} \leq C_{t}$. The term $\rho_{s s^{*}}$ reflects the "spillover" of information from the overnight to daytime segments of the $24 \mathrm{~h}$ day. Let the sigma-algebra $\Im_{O_{t}}$ denote the conditioning information set that contains all the information available up to the market opening at $O_{t}$. Conditional on $\Im_{O_{t}}$, the Brownian motions $W_{o, t}$ and $W_{d, t}$ are uncorrelated instead. This result follows from the Law of Iterated Expectations: $E\left[d W_{o, s} d W_{d, s^{*}}\right]=E\left[E\left[d W_{o, s} d W_{d, s^{*}} \mid \Im_{O_{t}}\right]\right]=E\left[d W_{o, s} E\left[d W_{d, s^{*}} \mid \Im_{O_{t}}\right]\right]=0$, since $E\left[d W_{d, s^{*}} \mid \Im_{O_{t}}\right]=0$ for all $s^{*} \in\left[O_{t}, C_{t}\right]$, by definition of a Brownian motion. 
According to Equation (3) the daily return can be decomposed as $r_{t}=r_{0, t}+r_{d, t}$ where $r_{0, t} \equiv p_{O_{t}}-p_{C_{t-1}}$ and $r_{d, t} \equiv p_{C_{t}}-p_{O_{t}}$ represent the overnight and daytime return processes

$$
r_{o, t}=\int_{C_{t-1}}^{O_{t}} \mu_{o, s} d s+\int_{C_{t-1}}^{O_{t}} \sigma_{o, s} d W_{o, s} \equiv \mu_{o, t}+\varepsilon_{o, t}
$$

and

$$
r_{d, t}=\int_{O_{t}}^{C_{t}} \mu_{d, s^{*}} d s^{*}+\int_{O_{t}}^{C_{t}} \sigma_{d, s^{*}} d W_{d, s^{*}}+\sum_{O_{t} \leq s^{*} \leq C_{t}} \kappa_{d, s^{*}} d q_{d, s^{*}} \equiv \mu_{d, s^{*}}+\varepsilon_{d, t},
$$

respectively. We define $\mu_{o, t} \equiv \int_{C_{t-1}}^{O_{t}} \mu_{o, s} d s$ as the integrated deterministic drift driving the overnight return, and $\varepsilon_{o, t} \equiv \int_{C_{t-1}}^{O_{t}} \sigma_{o, s} d W_{o, s}$ as its random component. Similarly, $\mu_{d, t} \equiv \int_{O_{t}}^{C_{t}} \mu_{d, s^{*}} d s^{*}$ is the integrated deterministic drift driving the daytime return and $\varepsilon_{d, t} \equiv \int_{O_{t}}^{C_{t}} \sigma_{d, s^{*}} d W_{d, s^{*}}+\sum_{O_{t} \leq s^{*} \leq C_{t}} \kappa_{d, s^{*}} d q_{d, s^{*}}$ its random component. The daily quadratic variation is

$$
Q V_{t}=I V_{t}+\sum_{O_{t} \leq s^{*} \leq C_{t}} \kappa_{d, s^{*}}^{2}
$$

with $I V_{t}$ the integrated variance of the return process $r_{t}$. This process is the sum of the integrated variances of the overnight and daytime components which can be expressed as

$$
I V_{t}=I V_{o, t}+I V_{d, t}
$$

with $I V_{o, t} \equiv V\left(r_{o, t}\right)=\int_{C_{t-1}}^{O_{t}} \sigma_{o, s}^{2} d s$ and $I V_{d, t} \equiv V\left(r_{d, t}\right)=\int_{O_{t}}^{C_{t}} \sigma_{d, s^{*}}^{2} d s^{*}$. This framework paves the way for two modeling approaches for the mean and variance components of the close-to-close return process (inputs to the location-scale VaR measure) which are discussed next.

\subsection{Bivariate Modeling Approach}

Let us formalize the overnight and daytime return data generating processes (DGP) as

$$
r_{0, t}=\mu_{0, t \mid t-1}+\varepsilon_{0, t}
$$

where $\mu_{0, t \mid t-1} \equiv E\left[r_{0, t} \mid \Im_{t-1}\right]$ is the conditional mean of the overnight return, and

$$
r_{d, t}=\mu_{d, t \mid t-1}+\varepsilon_{d, t}
$$

where $\mu_{d, t \mid t-1} \equiv E\left[r_{d, t} \mid \Im_{t-1}\right]$ is the conditional mean of the daytime return. The conditional quadratic variation of $r_{o, t}$ is $Q V_{o, t \mid t-1} \equiv I V_{o, t \mid t-1}=E\left[\varepsilon_{o, t}^{2} \mid \Im_{t-1}\right]$ under the absence of jumps in the overnight component. The conditional quadratic variation for the daytime process is $Q V_{d, t \mid t-1} \equiv I V_{d, t \mid t-1}+J_{d, t \mid t-1}$ with $J_{d, t \mid t-1}$ the jump component of the predicted daily quadratic variation process. The conditional quadratic covariation process $Q V_{o, d, t} \mid t-1$ is defined, by construction, as $I V_{o, d, t \mid t-1}=\operatorname{Cov}\left(r_{o, t}, r_{d, t} \mid \Im_{t-1}\right)=E\left[\varepsilon_{0, t} \varepsilon_{d, t} \mid \Im_{t-1}\right]$. This is so in model (3) because of two facts. First, the occurrence of cojumps between the overnight and daytime return is zero, and second, spillovers from the random process $d W_{o, s}$ to the daily discrete jump process $\kappa_{d, s^{*}} d q_{d, s^{*}}$ are also zero. As noted above, a non-zero covariance term, $\operatorname{Cov}\left(r_{o, t}, r_{d, t} \mid \Im_{t-1}\right)$, is possible if the overnight information is slowly impounded into prices at the market open for some of the portfolio constituents.

Recalling that $r_{t}=r_{0, t}+r_{d, t}$, by simple algebra the DGP of daily returns is $r_{t}=\mu_{t \mid t-1}+\varepsilon_{t}$ with $\varepsilon_{t}=\varepsilon_{0, t}+\varepsilon_{d, t}$. The conditional mean process $\mu_{t \mid t-1} \equiv E\left[r_{t} \mid \Im_{t-1}\right]$ can be expressed as

$$
\mu_{t \mid t-1}=\mu_{o, t \mid t-1}+\mu_{d, t \mid t-1}
$$


and the conditional quadratic variation process, $Q V_{t \mid t-1}$, can be decomposed as

$$
Q V_{t \mid t-1}=I V_{o, t \mid t-1}+Q V_{d, t \mid t-1}+2 I V_{o, d, t \mid t-1}
$$

In order to operationalize these expressions into forecasts $\widehat{\mu}_{t \mid t-1}$ and $\widehat{I V}_{t \mid t-1}$ we allow the conditioning information set $\Im_{t-1}$ to comprise the time-series $\left\{r_{0,1}, r_{o, 2}, \ldots, r_{0, t-1}\right\},\left\{r_{d, 0}, r_{d, 1}, \ldots, r_{d, t-1}\right\}$ and $\left\{R V_{1}, R V_{2}, \ldots, R V_{t-1}\right\}$. The first two time-series are historical daily returns directly derived from observed open and close market prices, $r_{0, t} \equiv \log \frac{P_{O, t}}{P_{C_{t-1}}}$ and $r_{o, t} \equiv \log \frac{P_{\mathrm{O}, t}}{P_{C_{t-1}}}$. The third time-series is a history of ex post "observed" daily realized variances - the sums of intraday squared returns-which can be cast as a realization from the integrated variance process. ${ }^{4}$

Following Andersen et al. [15], we acknowledge the strong volatility clustering of the overnight return. To do so we fit by quasi maximum likelihood (QML) an autoregressive (AR) equation for the return and the threshold GARCH (GJR-GARCH) model of Glosten, Jagannathan, and Runkle [28] for the volatility, both conditional on $\Im_{t-1}$. Formally, the overnight model is

$$
\begin{aligned}
& r_{o, t}=a_{0}+a_{1} r_{d, t-1}+b_{1} r_{o, t-1}+\sqrt{h_{o, t}} \cdot \epsilon_{o, t} \\
& h_{o, t}=\alpha_{0}+\alpha_{1} \varepsilon_{o, t-1}^{2}+\beta_{1} h_{o, t-1}+\gamma_{1} I_{t-1}^{-} \varepsilon_{t-1}^{2}
\end{aligned}
$$

where $\varepsilon_{0, t} \equiv \sqrt{h_{0, t}} \cdot \epsilon_{0, t}$ is the overnight innovation; $\epsilon_{0, t}$ is assumed to follow an i.i.d. skewed Student- $t\left(0,1, \xi_{0}, \eta_{0}\right)$ distribution where $\xi_{0}$ is the asymmetry parameter, and $\eta_{0}$ is the degrees of freedom (dof) parameter that captures the degree of fat-tailedness in the overnight return distribution. The term $\varepsilon_{t}$ denotes the innovation in a standard AR(1) model for the daily return $r_{t}$; accordingly, the volatility asymmetry indicator function is $I_{t}^{-}=1$ if $\varepsilon_{t}<0$ and $I_{t}^{-}=0$ otherwise. Accordingly, a parameter value $\gamma_{1}>0$ implies that large negative innovations or bad news at $t-1$ increase the day $t$ conditional volatility of overnight returns more than large positive innovations (the so-called leverage effect).

On the other hand, forecasts of the daytime return and quadratic variation process conditional on the information set $\Im_{t-1}$ are obtained through an AR equation to the open-to-close returns and a long memory $\operatorname{ARFIMA}(0, d, 1)$ equation for the realized variance. Formally ${ }^{5}$

$$
\begin{gathered}
r_{d, t}=a_{0}+a_{1} r_{d, t-1}+b_{1} r_{o, t-1}+\sqrt{\sigma_{d}^{2} \cdot R V_{t \mid t-1}} \cdot \epsilon_{d, t} \\
(1-L)^{d}\left(\ln R V_{t}-\tau_{0}-\tau_{1} r_{t-1}-\tau_{2} I_{t-1}^{-} r_{t-1}\right)=(1+\theta L) u_{t}
\end{gathered}
$$

where the standardized innovation $\epsilon_{d, t}$ is assumed i.i.d. skewed Student- $t\left(0,1, \xi_{d}, \eta_{d}\right)$, the innovation $u_{t}$ is i.i.d. $\left(0, \sigma_{u}^{2}\right)$; and the asymmetry or leverage indicator function is defined as $I_{t}^{-}=1$ if $r_{t}<0$ and $I_{t}^{-}=0$ otherwise; therefore, a parameter value $\tau_{2}<0$ implies that bad news on day $t-1$ increase the current daytime volatility more than good news. The ARFIMA modeling approach is motivated by the stylized long memory and log-normality properties of the realized variance. The AR-ARFIMA model parameters can be consistently estimated using Giot and Laurent's [21] two-pass approach. First, Equation (11b) is estimated by ML under a normality assumption for $u_{t}$. Second, Equation (11a) is estimated by QML under the assumption that the dynamic behaviour of the conditional volatility is ARFIMA type.

4 Barndorff-Nielsen and Shephard [25] show that $R V_{t}$ converges to $Q V_{t}$ as $M \rightarrow \infty$ at rate $\sqrt{M}$ where $M$ denotes the intraday sampling frequency. As a byproduct of this, these authors show that the realized variance is a consistent estimator of the sum of the integrated daily variance process and the sum of the daytime jumps.

5 Other specifications that have been used in the empirical finance literature to approximate the long memory properties of the realized volatility are Corsi's [26] heterogeneous autoregressive (HAR) model and Ghysels et al.'s [27] Mixed Data Sampling (MIDAS) model both of which combine information sampled at different frequencies. 
The advantage of this bivariate framework, as proposed in Ahoniemi et al. [5], is not only its flexibility to model separately the overnight and daytime return processes, $r_{o, t}$ and $r_{d, t}$, but also to model their covariance. For the latter purpose, these authors extend the dynamic conditional correlation (DCC) model of Engle [29] to the current setting where a GARCH model characterizes the overnight conditional variance and an ARFIMA realized volatility model characterizes the daytime conditional variance $^{6}$. The DCC equation employed in our subsequent VaR forecasting exercise is

$$
q_{o, d, t}=\bar{\rho}_{o, d}(1-\alpha-\beta)+\alpha \epsilon_{o, t-1} \epsilon_{d, t-1}+\beta q_{o, d, t-1}
$$

where $\epsilon_{0, t}$ and $\epsilon_{d, t}$ denote the standardized overnight and daytime innovations which, as explained above, are consistently estimated through the AR-GJR-GARCH and AR-ARFIMA parameterizations (10b) and (11b), respectively. The conditional correlation is denoted $q_{o, d, t}$. The conditional covariance term is obtained from $\varepsilon_{0, t}$ and $\varepsilon_{d, t}$ as $I V_{o, d, t}=q_{o, d, t} \sqrt{R V_{t} \times h_{o, t}}$.

\subsection{Univariate Ex Post Overnight Modeling Approach}

We now position the VaR forecaster at the market open of day $t$ so that the conditioning information set is the sigma-algebra $\Im_{O_{t}}$ which includes the day $t$ overnight close-to-open return. In this setup, a conditional mean forecast of the daily return can be obtained as $E\left[r_{t} \mid \Im_{O_{t}}\right]=r_{o, t}+\mu_{d, t \mid O_{t}}$ and the conditional quadratic variation as $Q V_{d, t \mid O_{t}}$. The question of interest is whether these mean and quadratic variation forecasts lead to day-ahead VaR measures that are more accurate than those obtained with the bivariate approach outlined in the previous section. This question is not trivial. On the one hand, the risk manager that constructs the equity VaR limit for day $t$ at time $O_{t}$ is exploiting a richer information set as she is able to incorporate the ex post observed overnight price variation. On the other hand, she loses any forecasting power coming from modeling the dynamics of the overnight return and the conditional covariance between overnight and daytime returns. Moreover, the effectiveness of the conditioning approach on $\Im_{O_{t}}$ implicitly hinges on the assumption that the market is efficient so that the open price, $p_{O_{t}}$, reflects all news accumulated overnight. This may not be the case if, in the context of broad stock indices, the opening price level suffers from "staleness" because not all stocks begin trading immediately or because the trading volume of some stocks may not be large enough for the opening price to be informative.

The forecasts $\mu_{d, t \mid O_{t}}$ and $Q V_{d, t \mid O_{t}}$ are obtained through AR-ARFIMA equations similar in spirit to the above Equations (11a) and (11b) with the only difference that the overnight close-to-open return $r_{o, t}$ is now part of the conditioning information set $\left(\Im_{O_{t}}\right)$. The ex post overnight model equations are

$$
\begin{gathered}
r_{d, t}=a_{0}+a_{1} r_{d, t-1}+b_{1} r_{o, t-1}+b_{0} r_{o, t}+\sqrt{\sigma_{d}^{2} \cdot R V_{t \mid O_{t}}} \cdot \epsilon_{d, t} \\
(1-L)^{d}\left(\ln R V_{t}-\tau_{0}-\tau_{1} r_{t-1}-\tau_{2} I_{t-1}^{-} r_{t-1}-\tau_{3} r_{o, t}-\tau_{4} I_{o, t}^{-} r_{o, t}\right)=\left(1+\theta_{1} L\right) u_{t}
\end{gathered}
$$

where $\epsilon_{d, t}$ is skewed Student- $t\left(0,1, \xi_{d}, \eta_{d}\right)$ distributed. There is a modeling strategy in the literature that broadly resembles this univariate approach in that AR-ARFIMA equations are fitted to time-series of daily open-to-close returns and realized volatilities computed from open-to-close intraday prices (e.g., Wu [31]; Liu and Maheu [32]; Fuertes et al. [33]; Corsi et al. [16]). In addition, we exploit the overnight return that is available at the market open when the forecasts are made.

6 Aielli [30] proves that the standard DCC method can yield inconsistent estimates of the model parameters for large systems that invalidate the traditional interpretation of the DCC correlation parameters. This author also proposes a cDCC procedure based on reformulating the DCC correlation driving process as a linear multivariate generalized autoregressive conditional heteroscedasticity (MGARCH) process. For consistency with the univariate specifications of the conditional volatility of the daytime and overnight return processes presented in this paper, we use, instead, the version of the DCC model proposed in Ahoniemi et al. [5]. 


\section{Risk Management Framework}

\subsection{VaR Forecasts}

A routine task of risk managers is to set daily 1\% Value-at-Risk (VaR) limits for separate business lines or 'desks' (e.g., equity, FX, fixed income) which amounts to predicting a specific quantile of the daily portfolio return distribution. The one-day $1 \% \mathrm{VaR}$ of a given portfolio is the maximum dollar-amount loss over a one-day horizon that should be exceeded only $1 \%$ of the time. The VaR measure has been used by banks since the 1990s as a one-dimensional snapshot of downside risk. Real-time risk monitoring using VaR has the advantage that VaR limits are comparable across assets and forward-looking in nature. The widespread use of VaR as an internal measure of risk by banks was formally acknowledged by the Basel Accord which introduced in 1996 a VaR-based capital requirement framework for positions held for trading intent [34].

VaR-based risk limits can be obtained using non-parametric (e.g., historical simulation), semi-parametric (e.g., CAViaR) and parametric (e.g., GARCH) techniques depending on the number of assumptions one is prepared to make on the daily return distribution. ${ }^{7}$ The parametric VaR approach remains the most widely used by academics, regulators and risk managers. It builds on the assumption that returns belong to a location-scale density which implies, in effect, that the quantile is an affine function of the volatility (see e.g., Giot and Laurent [21]; Giacomini and Komunjer [37]; Clements et al. [38]; Brownlees and Gallo [39]; Fuertes and Olmo [23].

The goal is to obtain out-of-sample forecasts for the $\alpha$-quantile of the conditional distribution of the day $t$ return process; we denote the forecast target $\operatorname{VaR}_{t, \alpha} \equiv F_{t}^{-1}(\alpha)$ where $F_{t}^{-1}(\cdot)$ is the inverse of the conditional distribution of $r_{t}$ given the sigma-algebra $\Im$ that represents the information set available to the risk manager at the time the forecast is made. The forecast target can be rewritten as $P\left(r_{t} \leq \operatorname{VaR}_{t, \alpha} \mid \Im_{t-1}\right)=\alpha .^{8}$

Our preferred model for the daily close-to-close return is location-scale type, formalized as $r_{t}=\mu_{t}+\sqrt{Q V_{t}} \epsilon_{t}$, where $\mu_{t}$ and $\sqrt{Q V_{t}}$ are the mean and quadratic variation of the close-to-close return distribution; $\epsilon_{t}$ is an standardized innovation. By assuming that $Q V_{t}$ and $\epsilon_{t}$ are independent processes, the corresponding prediction for the $\alpha$-quantile is given by

$$
V a R_{t, \alpha}=\mu_{t}+\sqrt{Q V_{t}} F_{\epsilon}^{-1}(\alpha)
$$

where $F_{\epsilon}^{-1}(\alpha)$ is the $\alpha$-quantile of $\epsilon_{t}$. The conditional mean and variance equations portrayed in Sections 2.2 (bivariate approach) and 2.3 (ex post overnight approach) are the building blocks to obtain forecasts of $\mu_{t}$ and $Q V_{t}$ in (15).

The bivariate-based VaR prediction, following the discussion in Section 2.2, is an $\alpha$-quantile forecast conditional on the information set $\Im_{t-1}$ which can be formalized as

$$
V a R_{t \mid t-1, \alpha}^{\text {bivariate }}=\mu_{t \mid t-1}+\sqrt{Q V_{t \mid t-1}} F_{\epsilon}^{-1}(\alpha)
$$

where the first term $\mu_{t \mid t-1}$ is obtained as the sum of two forecasts from the overnight and daytime AR equations, (9a) and (10a), respectively, $\mu_{t \mid t-1}=\mu_{o, t \mid t-1}+\mu_{d, t \mid t-1}$ according to decomposition (8); the term $Q V_{t \mid t-1}$ is obtained by aggregating three forecasts, respectively, from the overnight GJR-GARCH Equation (9b), daytime ARFIMA Equation (10b) and DCC Equation (11), that is, $Q V_{t \mid t-1}=I V_{o, t \mid t-1}+Q V_{d, t \mid t-1}+2 I V_{o, d, t \mid t-1}$, according to decomposition (9). The $\alpha$-quantile of the skewed Student- $t$ distributed daily standardized innovation $\epsilon_{t}$ is denoted $F_{\epsilon}^{-1}(\alpha)$.

7 For recent surveys on VaR modeling, see Kuester et al. [35] and Angelidis and Degiannakis [36].

8 Our interest is in long trading positions. For short trading positions one would analyze instead the right tail, i.e., $F_{t}^{-1}(1-\alpha)$. Commercial banks are required to report VaR at confidence level $99 \%$ to regulators but most banks adopt the $95 \%$ level for internal backtesting. We consider both coverage levels $\alpha=\{0.01,0.05\}$. 
The ex post overnight VaR prediction, following the discussion in Section 2.3, is an $\alpha$-quantile forecast conditional on the information set $\Im_{O_{t}}$ that includes the day $t$ overnight period. Formally,

$$
V a R_{t \mid O_{t}, \alpha}^{\text {expost }}=\mu_{t \mid O_{t}}+\sqrt{Q V_{t \mid O_{t}}} F_{\epsilon_{d}}^{-1}(\alpha),
$$

where $\mu_{t \mid O_{t}}=r_{o, t}+\mu_{d, t \mid O_{t}}$ since the ex post overnight return is available. The daytime conditional mean forecast $\mu_{d, t \mid O_{t}}$ is obtained from the AR(1) Equation (13a) and the daytime conditional quadratic variation forecasts $\widehat{Q V}_{d, t \mid O_{t}}$ from the ARFIMA Equation (13b); $F_{\epsilon_{d}}^{-1}(\alpha)$ is the $\alpha$-quantile of the skewed Student- $t$ distributed daytime standardized innovation $\epsilon_{d, t}$.

The various methods to compute one-day-ahead VaR forecasts are compared using two statistical methods. First, we utilize the unconditional version of the predictive ability test for quantiles developed by Giacomini and White [11]. Second, we conduct two backtesting exercises to assess whether the conditional VaR models are correctly specified. We briefly outline these evaluation methods next. To simplify the exposition, we denote the relevant information set as $\Im_{t-1}$ throughout the section but the equations can be straightforwardly modified to use instead $\Im_{O_{t}}$ without loss of generality.

\subsection{Predictive Ability Tests}

VaR measurement is an out-of-sample forecasting exercise and, as such, the evaluation of competing VaRs can be based on predictive ability tests. These tests compare the average losses associated with two or more competing forecasting models. The predictive ability testing literature, dating back to Diebold and Mariano [40], West [41], and West and McCracken [42] amongst others, was subsequently extended to a conditional framework by Giacomini and White [11].

To establish notation, let $\theta_{0}$ denote the true (unknown) vector of parameters in the mean and variance equations. Let the in-sample (estimation) period comprise $P$ days and the out-of-sample (evaluation) period comprise $n$ days with $P+n=T$. A rolling estimator of $\theta_{0}$ based on the sample window $[t-1, t-P]$ is denoted $\widehat{\theta}_{P, t-1}$ hereafter.

Since our target variable is the conditional $\alpha$-quantile of the daily return $r_{t}$ distribution, the most suitable loss function is the asymmetric linear loss function of order $\alpha$ defined as

$$
L_{t}\left(e_{t}\left(\widehat{\theta}_{P, t-1}\right)\right)=\left(\alpha-1\left(e_{t}\left(\widehat{\theta}_{P, t-1}\right)<0\right)\right) e_{t}\left(\widehat{\theta}_{P, t-1}\right)
$$

where $1(\cdot)$ is a binary indicator function and the forecast error is defined as $e_{t}\left(\widehat{\theta}_{P, t-1}\right)=\left(r_{t}-\operatorname{VaR}_{t, \alpha}\left(\widehat{\theta}_{P, t-1}\right)\right)$. Equation (17) is known as the "tick" or "check" loss function in the literature. We deploy the unconditional predictive ability test for quantiles developed by Giacomini and White [11] based on this loss function and OLS regression analysis. The null hypothesis of the test is

$$
H_{0}: E\left[\Delta L_{t}\right]=0 \text {, almost surely for } t=P+1, \ldots, T,
$$

with $\Delta L_{t}=L_{t}\left(e_{t}^{1}\left(\widehat{\theta}_{P, t-1}\right)\right)-L_{t}\left(e_{t}^{2}\left(\widehat{\theta}_{P, t-1}\right)\right)$; where $e_{t}^{1}$ and $e_{t}^{2}$ are the out-of-sample errors associated with the $\mathrm{VaR}$ forecasts from Models 1 and 2, respectively. The aim of this test is therefore to assess differences in the average losses associated with two competing VaR models. We focus on the one-sided version of the test with null and alternative hypotheses $H_{0}: E\left[\Delta L_{t}\right] \leq 0$ and $H_{a}: E\left[\Delta L_{t}\right]>0$, respectively. Rejection of the null hypothesis implies that the average loss of Model 1 is greater than that of Model 2. The test is based on an out-of-sample $t$-statistic computed as $\sqrt{n}$ times the ratio of the sample mean of $\Delta L_{t}$ to its sample standard deviation using the Newey and West [43] robust variance estimator. In essence, this amounts to running an OLS regression of the loss differential sequence $\Delta L_{t}$ on a constant and testing for the significance of the constant. 


\subsection{Backtesting}

VaR backtesting is aimed at assessing whether the model at hand is correctly specified. A correctly specified $\alpha$-th conditional VaR model of the portfolio returns $r_{t}$ is defined as

$$
P\left(r_{t} \leq \operatorname{VaR}_{t, \alpha}\left(\theta_{0}\right) \mid \Im_{t-1}\right)=\alpha \text {, almost surely (a.s.), } \alpha \in(0,1), \forall t \in \mathbb{Z} \text {. }
$$

This definition of correct VaR specification is typically found in theoretical VaR discussions (Christoffersen et al. [44]; Engle and Manganelli [12]; Koenker and Xiao [45]; Fuertes and Olmo [23]. Let the out-of-sample demeaned hits or violations be denoted by $\operatorname{Hit}_{t, \alpha}\left(\theta_{0}\right) \equiv 1\left(r_{t} \leq \operatorname{VaR}_{t, \alpha}\left(\theta_{0}\right)\right)-\alpha$. If criterion (19) is met, then it follows that the expected value of $\operatorname{Hit}_{t, \alpha}\left(\theta_{0}\right)$ conditional on the information set $\Im_{t-1}$ is zero which, in turn, implies that $\operatorname{Hit}_{t, \alpha}\left(\theta_{0}\right)$ is independent of any function of the variables contained in $\Im_{t-1}$. Intuitively, correct VaR specification means that future hits should be unpredictable.

A formal assessment of the adequacy of the out-of-sample VaR forecasts through the "lens" of criterion (19) can be conducted through the dynamic quantile (DQ) test of Engle and Manganelli [12]. ${ }^{9}$

$$
\operatorname{Hit}_{t, \alpha}\left(\widehat{\theta}_{P, t-1}\right)=x_{t-1}\left(\widehat{\theta}_{P, t-1}\right) \gamma+v_{t}, t=P+1, \ldots, T, n=T-P
$$

where $\gamma$ is a $k \times 1$ parameter vector (including an intercept) and $v_{t}$ is a zero-mean iid error sequence. The null hypothesis of correct conditional coverage, $H_{0}: E\left[\operatorname{Hit}_{t, \alpha}\left(\widehat{\theta}_{P, t-1}\right) \mid x_{t-1}\left(\widehat{\theta}_{P, t-1}\right)\right]=0$, where $x_{t-1}\left(\widehat{\theta}_{P, t-1}\right)$ is a vector of $k$ regressors, can be stated in this testing framework as $H_{0}: \gamma_{0}=$ $\gamma_{1}=\ldots=\gamma_{k-1}=0$. The corresponding Wald test statistic is given by

$$
D Q=n \frac{\widehat{\gamma}_{n}^{\prime}\left[M_{n}\left(\widehat{\theta}_{P}\right)\right] \widehat{\gamma}_{n}}{\alpha(1-\alpha)}
$$

where $M_{n}\left(\widehat{\theta}_{P}\right)=\frac{1}{n} \sum_{t=P+1}^{T} x_{t-1}^{\prime}\left(\widehat{\theta}_{P, t-1}\right) x_{t-1}\left(\widehat{\theta}_{P, t-1}\right)$ is a $k \times k$ matrix, and $\widehat{\gamma}_{n}$ is the OLS estimator of (20) which is consistent and asymptotically normally distributed. Under $H_{0}$ as $n \rightarrow \infty$, it can be shown that $D Q$ converges in distribution to a $\chi_{k}^{2}$ (i.e., $D Q \stackrel{d}{\rightarrow} \chi_{k}^{2}$ ).

The binary nature of the hits sequence induces heteroscedasticity in the error $v_{t}$ of model (20). Nonlinear probit or logit formulations have been recently deployed as refinements of (20) with the advantage that the fitted values (probabilities) are bounded between 0 and 1 by construction, and the asymptotic ML standard error formulae takes the heteroskedasticity into account (Taylor [19]; Berkowitz et al. [47]). In our analysis, we adopt the probit regression model

$$
E\left[1\left(r_{t} \leq \operatorname{VaR}_{t, \alpha}\left(\widehat{\theta}_{P, t-1}\right)\right) \mid x_{t-1}\left(\widehat{\theta}_{P, t-1}\right)\right]=\Phi\left(x_{t-1}\left(\widehat{\theta}_{P, t-1}\right) \beta\right), t=P+1, \ldots, T
$$

with $\Phi(\cdot)$ the cumulative standard Normal distribution and $\beta \equiv\left(\beta_{0}, \beta_{1}, \ldots, \beta_{k-1}\right)^{\prime}$ the regression parameter vector. In this probit setting, the correct conditional coverage criterion (19) amounts to

$$
E\left[1\left(r_{t} \leq \operatorname{VaR}_{t, \alpha}\left(\widehat{\theta}_{P, t-1}\right)\right) \mid x_{t-1}\left(\widehat{\theta}_{P, t-1}\right)\right]=\Phi\left(\beta_{0}\right)=\alpha
$$

which can be stated as $\widetilde{H}_{0}: \beta_{0}=\Phi^{-1}(\alpha), \beta_{1}=\ldots=\beta_{k-1}=0$, and tested through the LR statistic

$$
D B=2\left(\mathcal{L}-\mathcal{L}_{0}\right)
$$

9 Other conditional coverage tests have been developed based on the duration between consecutive violations; see e.g., Candelon et al. [46] The test is based on OLS estimation of the linear probability model 
with $\mathcal{L}=\sum_{t=P+1}^{T}\left[\operatorname{Hit}_{t, \alpha}\left(\widehat{\theta}_{P, t-1}\right) \ln \Phi\left(x_{t-1}\left(\widehat{\theta}_{P, t-1}\right) \widehat{\beta}_{n}\right)+\left(1-\operatorname{Hit}_{t, \alpha}\left(\widehat{\theta}_{P, t-1}\right)\right) \ln \left(1-\Phi\left(x_{t-1}\left(\widehat{\theta}_{P, t-1}\right) \widehat{\beta}_{n}\right)\right)\right]$ the log-likelihood of (22), and $\widehat{\beta}_{n}$ its ML estimator which is consistent and asymptotically normal. Under $\widetilde{H}_{0}$, it follows that $\mathcal{L}_{0}=\sum_{t=P+1}^{T}\left[\operatorname{Hit}_{t, \alpha}\left(\widehat{\theta}_{P, t-1}\right) \ln \alpha+\left(1-\operatorname{Hit}_{t, \alpha}\left(\widehat{\theta}_{P, t-1}\right)\right) \ln (1-\alpha)\right]$, and $D B \stackrel{d}{\rightarrow} \chi_{k}^{2}$.

We follow Engle and Manganelli [12], Dumitrescu et al. [48], Ahoniemi et al. [5] and others in deploying these backtesting tests using the expanded regressor set

$$
x_{t-1}\left(\widehat{\theta}_{P, t-1}\right)=\left(1, r_{t-1}, r_{t-1}^{2}, V_{a R} R_{t-1, \alpha}\left(\widehat{\theta}_{P, t-1}\right), \operatorname{Hit}_{t-1, \alpha}\left(\widehat{\theta}_{P, t-1}\right)\right),
$$

which controls for dependence between the day $t$ hit and the day $t-1$ return, volatility, VaR and hit.

\section{Empirical Application}

\subsection{Data and Descriptive Statistics}

Two major stock market indices are chosen as illustrative equity portfolios: S\&P 500 and Russell 2000. S\&P 500 is by far the most common benchmark for funds (mutual funds, ETFs, and pension funds) that identify themselves as large cap. Russell 2000 is the typical benchmark for small cap funds. The observations are 5-minute quotations from 9:30-16:00 Eastern time (EST) which amounts to $M=78$ intraday intervals. The quotes are from Disk Trading (http://www.is99.com/disktrading/). Although methods exist to choose the "optimal"sampling frequency for realized variance estimation (see e.g., the MSE minimization approach by Bandi and Russell [49]), we follow most of the stock realized volatility literature in adopting the 5-minute sampling frequency. This is the typical sampling interval because, for highly liquid stocks, it has been shown to be short enough for the daily volatility dynamics to be picked up with reasonable accuracy (small estimation error) and long enough for the adverse effects of market microstructure noise (e.g., bid-ask bounce, discrete price observations, irregular trading) not to be excessive. The observed opening price on day $t$ is the first price recorded after 9:30. The $j$ th intra-day price $p_{t, j}$ with $j=1, \ldots, M-1$ is defined as the last seen tick before the $j$ th 5 -minute mark. The day $t$ closing price $p_{C_{t}} \equiv p_{t, M}$ is defined as the last price observed before 16:00. The two equity portfolios are observed over the most recent 15-year period available from 12 November 1997 to 31 September 2011 ( $T=3491$ trading days). As of September 2011, the S \& P 500 index comprises roughly 20\% Nasdaq-traded (89/500) and 80\% NYSE-traded (411/500) companies, whereas for the Russell 2000, the breakdown is roughly $60 \%$ Nasdaq $(1250 / 2000)$ and $40 \%$ NYSE $(750 / 2000)$. Measured by trading volume, there is a marked difference between large and small cap U.S. equities: the average daily trading volume from 1 January 2011 to 30 December 2011 for the S\&P 500 (Russell 2000) constituents is about $\$ 41$ billion ( $\$ 40$ million).

Table 1 summarizes the daily overnight and daytime return distribution from 12 November 1998 to 29 August 2008 (pre-Lehman) and 2 September 2008 to 30 September 2011 (post-Lehman).

For both indices and over both sub-periods (pre- and post-Lehman) the summary statistics confirm previous stylized facts: stock return volatility is substantially higher in the daytime (trading) than the overnight (non-trading) segments of the day. Unsurprisingly, both daytime and overnight return variances increase dramatically post-Lehman. During the pre-Lehman period, the marked negative skewness and high kurtosis of overnight returns represent a large contrast vis-à-vis the corresponding higher moments of daytime returns; however, this contrast is notably blurred during the post-Lehman period when the daytime returns also become markedly negatively skewed and kurtosed. The kurtosis of overnight returns is about three times larger than that of daytime returns in the pre-Lehman period, but becomes roughly similar for both segments of the day during the post-Lehman period. Overnight and daytime returns pertaining to the same day $\left(r_{o, t}, r_{d, t}\right)$ are strongly positively correlated throughout, but there is a substantial increase in correlation from the pre- to the post-Lehman periods. Overnight 
and daytime returns exhibit some 1st order autocorrelation, typically negative, but in much milder form daytime. The magnitude of both autocorrelations increases somewhat in the post-Lehman period.

Table 1. Descriptive statistics for overnight and daytime returns.

\begin{tabular}{|c|c|c|c|c|c|c|c|c|}
\hline & \multicolumn{4}{|c|}{ In-Sample November 1997-August 2008} & \multicolumn{4}{|c|}{ Out-of-Sample September 2008-September 2011} \\
\hline & \multicolumn{2}{|c|}{ Russell 2000} & \multicolumn{2}{|c|}{ S \& P 500} & \multicolumn{2}{|c|}{ Russell 2000} & \multicolumn{2}{|c|}{ S \& P 500} \\
\hline & $\begin{array}{c}r_{o, t} \\
\text { night }\end{array}$ & $\begin{array}{l}r_{d, t} \\
\text { day }\end{array}$ & $\begin{array}{c}r_{o, t} \\
\text { night }\end{array}$ & $\begin{array}{l}r_{d, t} \\
\text { day }\end{array}$ & $\begin{array}{c}r_{o, t} \\
\text { night }\end{array}$ & $\begin{array}{l}r_{d, t} \\
\text { day }\end{array}$ & $\begin{array}{c}r_{o, t} \\
\text { night }\end{array}$ & $\begin{array}{l}r_{d, t} \\
\text { day }\end{array}$ \\
\hline \multicolumn{9}{|c|}{ Panel A: returns } \\
\hline Mean & 0.020 & 0.000 & 0.007 & 0.005 & -0.004 & -0.014 & -0.012 & -0.004 \\
\hline Median & 0.005 & 0.040 & 0.003 & 0.047 & 0.007 & 0.138 & 0.000 & 0.095 \\
\hline StDev & 0.234 & 1.271 & 0.190 & 1.092 & 0.572 & 2.136 & 0.249 & 1.780 \\
\hline Skewness & -0.525 & -0.074 & -0.249 & -0.031 & -0.283 & -0.358 & -0.254 & -0.362 \\
\hline Kurtosis & 19.80 & 4.026 & 14.99 & 5.600 & 6.930 & 6.015 & 7.774 & 8.586 \\
\hline \multicolumn{9}{|c|}{ Correlation structure: } \\
\hline$r_{o, t-1}$ & $-0.089^{* * *}$ & -0.028 & $-0.092^{* * *}$ & 0.001 & $-0.149^{* * *}$ & $-0.064^{*}$ & $-0.118^{* * *}$ & -0.026 \\
\hline$r_{d, t}$ & $0.162^{* * *}$ & & $0.202^{* * *}$ & & $0.273^{* * *}$ & & $0.390^{* * *}$ & \\
\hline$r_{d, t-1}$ & $0.041^{* *}$ & 0.015 & -0.011 & $-0.038^{* *}$ & -0.040 & $-0.085^{* *}$ & -0.048 & -0.122 \\
\hline$Q_{20}(\mathrm{ACF})$ & 60.6 & 38.64 & 60.78 & 35.21 & 36.62 & 28.07 & 37.12 & 52.53 \\
\hline Mean (hourly) & 0.003 & 0.248 & 0.002 & 0.183 & 0.019 & 0.701 & 0.004 & 0.487 \\
\hline Median & 0.006 & 0.597 & 0.004 & 0.361 & 0.096 & 1.120 & 0.011 & 0.457 \\
\hline StDev & 0.237 & 2.810 & 0.135 & 2.556 & 0.797 & 10.22 & 0.162 & 8.724 \\
\hline Skewness & 14.16 & 4.661 & 11.58 & 7.089 & 8.880 & 5.307 & 6.353 & 5.905 \\
\hline Kurtosis & 254.6 & 39.42 & 196.5 & 89.15 & 117.3 & 43.48 & 57.41 & 46.17 \\
\hline$Q_{20}(\mathrm{ACF})$ & 156.4 & 1697 & 247.9 & 1058 & 186.8 & 1151 & 441.3 & 1107 \\
\hline
\end{tabular}

The table summarizes the empirical distribution of daily overnight and daytime returns (Panel A) and the corresponding volatility measure given by the squared return (Panel B) over the post-Lehman period from 2 September 2008 to 31 September 2011 and the preceding period from 12 November 1997 to 29 August 2008. All returns are in percentages. The correlation structure section reports autocorrelations between the overnight return on day $t$ and day $t-1$, between the daytime return on day $t$ and day $t-1$, and the cross-correlation between the overnight return on day $t$ and daytime return on day $t . Q_{20}(\mathrm{ACF})$ is the Ljung-Box statistic for the null of no autocorrelation up to 20 lags. $*, * *$ and $* * *$ indicate significance at the $10 \%, 5 \%$ or $1 \%$ levels.

The overnight and daytime squared returns are summarized in Panel B of Table 1. To make the comparison more informative, we report the hourly volatility as the mean squared return divided by the number of hours spanned by each segment of the day, $17.5 \mathrm{~h}$ (overnight) and $6.5 \mathrm{~h}$ (daytime). Return volatility is higher in daytime than overnight, which is well aligned with market microstructure wisdom that information flow is greater during trading than non-trading hours. The volatility autocorrelation function shows a much slower decay at daytime (i.e., more persistence) than overnight. Both volatilities increase dramatically from the first to the second sample periods. Overall the statistics in Table 1 suggest important differences in the overnight and daytime return distributions.

\subsection{VaR Predictions and Evaluation}

Before discussing the VaR forecasts per se, we report in Table 2 the estimation results for the models outlined in Sections 2.2 and 2.3. The estimation window spans the entire 15-year sample period ( $T=3491$ days). The models are able to capture important stylized facts.

The overnight model estimates in Table 2, Panel A, top exhibit, reveal the presence of: (i) asymmetry in the conditional variance (leverage effect) as borne out by a significantly positive parameter $\gamma_{1}$; (ii) fat-tailedness in standardized overnight returns as reflected in a small dof parameter $\eta_{0}$; (iii) negative-skew in the distribution of innovations to the overnight portfolio return as suggested by $\ln \left(\xi_{0}\right)<0$. These findings justify the skewed Student- $t$ distributional assumption for the innovation process. The sufficient condition for stationarity, $\gamma_{1}<2\left(1-\alpha_{1}-\beta_{1}\right)$, is satisfied for both indices. 
Table 2. Model estimates and diagnostics from November 1997 to September 2011.

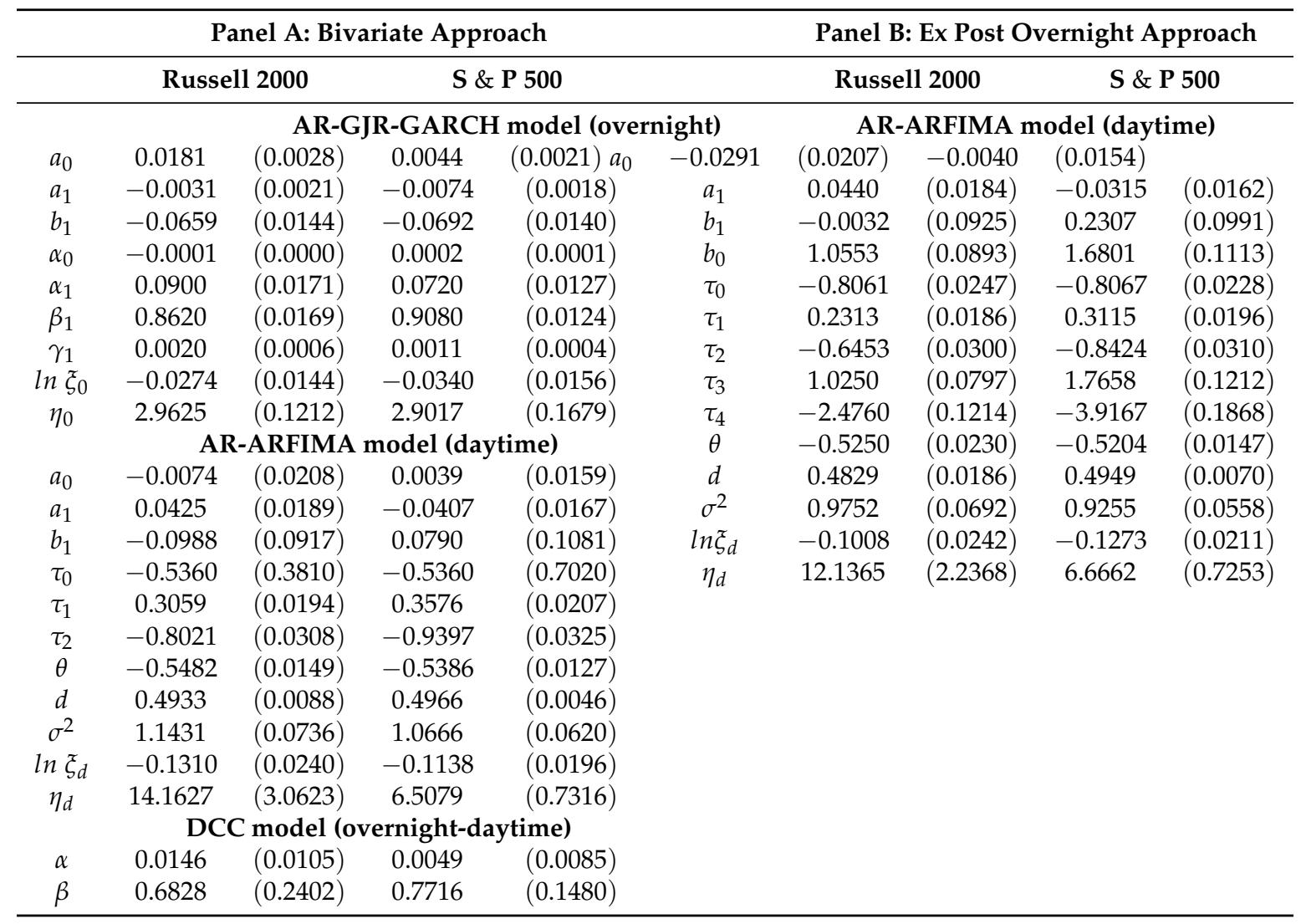

The table reports estimation results for the bivariate model discussed in Section 2.2 and the ex post overnight model discussed in Section 2.3. Panel A pertains to the bivariate modeling approach that amounts to constructing the VaR forecast for day $t$ at the close of day $t-1$; the overnight return process is AR-GJR-GARCH, Equations (9a)-(9b), the daytime return process is AR-ARFIMA, Equations (10a)-(10b), and the dynamic covariance is DCC, Equation (11). Panel B pertains to the ex post overnight model that amounts to constructing the VaR limit for day $t$ at the same-day market open; the daytime return process is AR-ARFIMA Equations (12a)-(12b). The overnight and daytime return processes are assumed to follow an asymmetric Student-t distribution with asymmetry parameter $\xi$ (the table reports the logarithmic transformation, $\ln \xi$, as it is typical in the literature) and fat-tailedness parameter $\eta$. The estimation period is November 1997 to September 2011. Standard errors are reported in parentheses.

The model estimates in Panel A, middle exhibit, and Panel B, both of which refer to the daytime trading period, suggest: (i) asymmetry in volatility as borne out by a significantly negative $\tau_{2}$ parameter in Panel A and significantly negative $\tau_{2}$ and $\tau_{4}$ parameters in Panel B, suggesting a stronger reaction of the volatility process to bad news than to good news; (ii) fat-tailedness but less so than the overnight return distribution as borne out by a larger dof parameter $\eta_{d}$; (iii) more marked negative skewness as suggested by the asymmetry parameter $\ln \left(\xi_{d}\right)$; (iv) the long-memory parameter $d>0$ confirms the slow hyperbolic autocorrelation decay of the logarithmic realized volatility; for both equity indices, $d$ is significantly less than $1 / 2$ suggesting a stationary but strongly persistent daytime realized volatility process. The asymmetry in daytime volatility and the fat-tailedness of daytime innovations are stronger for the S\&P 500 index than for the Russell 2000 index. Finally, the model estimates reported in the bottom exhibit of Panel A indicate that the sufficient stationarity condition, $\alpha_{1}+\beta_{1}<1$, is satisfied for the dynamic conditional correlation model.

We next analyze the outcome of the out-of-sample day-ahead VaR forecasting exercise. In this exercise, the first VaR forecast is based on the model parameter vector $\theta_{0}$ estimated with information from day 1 to $P$, denoted $\widehat{\theta}_{P}$, the second forecast is based on $\widehat{\theta}_{P+1}$ obtained from observations 2 through $P+1$, and so forth. The fixed length of the rolling estimation window is $P=2713$ days and hence, the out-of-sample forecasted period comprises $n=778$ days ( $T \equiv P+n=3491$ days). 
We perform the VaR forecast evaluation sequentially over $J=279$ rolling out-of-sample windows of fixed length $n_{j}, j=1, \ldots, J$, commencing on 2 September 2008. Each window spans a 2-year trading period ( $n_{j}=500$ days). First, we discuss the results of the unconditional predictive ability test. Second, we interpret the findings from the two backtesting procedures.

Table 3 provides the rejection frequencies of the predictive ability test over the 279 out-of-sample windows. The first column of the table confronts the bivariate approach and the simpler, nested bivariate approach without $(\mathrm{w} / \mathrm{o})$ the covariance term. For both equity indices and for both the $5 \%$ and $1 \%$ VaRs, the null hypothesis that the bivariate VaR forecasts are at least as accurate as those from the simpler bivariate model without $(\mathrm{w} / \mathrm{o})$ covariance is rejected in zero instances. This evidence suggests that the covariance term captures relevant information (e.g., news spillovers from the overnight period into the early part of the trading day) which serves to enhance the accuracy of out-of-sample VaR forecasts.

Table 3. Predictive ability test: rejection frequencies.

\begin{tabular}{lcc}
\hline & Bivariate w/o Covariance & Ex Post Overnight \\
\hline \multicolumn{3}{c}{ Panel A: Russell 2000 } \\
\hline 5\% VaR & 0.000 & 0.419 \\
\% VaR & 0.000 & 0.061 \\
\hline \multicolumn{3}{c}{ Panel B: S \& P 500 } \\
\hline $5 \% \mathrm{VaR}$ & 0.000 & 1.000 \\
$1 \% \mathrm{VaR}$ & 0.000 & 1.000
\end{tabular}

The table reports the rejection frequency of the one-sided unconditional predictive ability test of [11] over $J=279$ rolling out-of-sample windows of fixed length (500 days). The first window begins on 2 September 2008 and the last window begins on 8 October 2009. In the first column, the null hypothesis is that the bivariate model is at least as good as the simpler bivariate model without $(\mathrm{w} / \mathrm{o})$ covariance term. In the second column, the null hypothesis is that the bivariate model is at least as good as the ex post overnight model that conditions additionally on the same-day overnight return. Null hypothesis rejection indicates that the bivariate model is outperformed by the comparison model in terms of predictive ability.

In the second column of Table 3, we confront the bivariate approach with the ex post overnight approach. The null hypothesis is that the bivariate approach that generates the forecasts at the close of dat $t-1$ is at least as good as the ex post overnight approach that generates the forecasts at the open of day $t$ (including the overnight information). The ex post overnight model is superior to the bivariate model for the large cap S\&P 500 index - the null hypothesis is rejected in $100 \%$ of the out-of-sample periods. In sharp contrast, for the small cap Russell 2000 the bivariate model continues to be the better approach over most of the evaluation windows. Thus the predictive ability test reveals an important contrast between the S\&P 500 index and Russell 2000 index regarding the merit of constructing the VaR forecasts at the market open of day $t$ with the purpose of including the ex post overnight information. Doing so is only worthwhile for setting day-ahead trading (VaR) risk limits in the case of the high-volume S\&P 500 index.

To gain further insights into the performance of the bivariate and ex post overnight VaR forecasting approaches, we proceed to analyze the outcome of the dynamic quantile (DQ) test of Engle and Manganelli [12] and the dynamic binary (DB) probit-based variant. Table 4 summarizes the results. Panel A1 reports the percentage of rejections of the null hypothesis over the full set of 279 out-of-sample windows. Panels A2 and A3 report the percentage of rejections, respectively, over the first $1 / 10$ of windows that capture the brunt of the post-Lehman debacle (last out-of-sample 500-day window ends on 6 October 2010) and the remaining $9 / 10$ of windows that represent a relatively calmer period.

The rejection rates of the correct conditional coverage criterion, Equation (19), are computed first as $\sum_{j=1}^{J} w_{j} I\left(p_{j}<0.05\right)$ where $p_{j}$ is the $p$-value of the test in the $j$ th evaluation window, $w_{j} \equiv 1 / J$ and $J$ is the number of windows; $\widehat{\alpha}_{j}-\alpha_{j}>0$ implies tail risk underestimation. The rejection rates thus obtained (Panel A of Table 3) confirm that the ex post overnight approach produces the best VaR forecasts 
for the S\&P 500 index, whereas the bivariate approach works best for the Russell 2000 index. Therefore, despite the fact that the ex post overnight approach incorporates the close-to-open overnight return into the conditioning information set $\left(\Im_{\mathrm{O}_{t}}\right)$, the bivariate model can still produce more accurate VaR forecasts in relatively small-cap equity markets where the lower trading volumes imply that overnight news are not fully incorporated into the open price. A comparison across Panels A2 and A3 clearly suggest that the VaR forecasts improve throughout (both equity indices, irrespective of the model) from the initial post-Lehman period to the later post-Lehman period. As more of the extremely volatile post-Lehman days are incorporated into the estimation windows, the forecasts become gradually more accurate.

Table 4. VaR backtesting: rejection frequencies.

\begin{tabular}{|c|c|c|c|c|}
\hline & Bivariate & Ex Post Overnight & Bivariate & Ex Post Overnight \\
\hline & \multicolumn{2}{|c|}{ Russell 2000} & \multicolumn{2}{|c|}{ S \& P 500} \\
\hline \multicolumn{5}{|c|}{ Panel A1: Equally-weighted J backtesting windows $(J=279)$} \\
\hline DQ test (5\% VaR) & 0.222 & 0.480 & 0.237 & 0.032 \\
\hline DQ test $(1 \% \mathrm{VaR})$ & 0.291 & 0.097 & 0.251 & 0.237 \\
\hline Probit test (5\% VaR) & 0.151 & 0.741 & 0.566 & 0.097 \\
\hline Probit test (1\% VaR) & 0.068 & 0.097 & 0.835 & 0.194 \\
\hline \multicolumn{5}{|c|}{ Panel A2: Equally-weighted 1/3J backtesting windows } \\
\hline DQ test (5\% VaR) & 0.667 & 0.957 & 0.301 & 0.097 \\
\hline DQ test (1\% VaR) & 0.570 & 0.269 & 0.333 & 0.290 \\
\hline Probit test (5\% VaR) & 0.452 & 1.000 & 1.000 & 0.290 \\
\hline Probit test ( $1 \%$ VaR) & 0.204 & 0.290 & 0.677 & 0.312 \\
\hline \multicolumn{5}{|c|}{ Panel A3: Equally-weighted 2/3J backtesting windows } \\
\hline DQ test (5\% VaR) & 0.000 & 0.238 & 0.200 & 0.000 \\
\hline DQ test $(1 \%$ VaR) & 0.151 & 0.011 & 0.205 & 0.205 \\
\hline Probit test (5\% VaR) & 0.000 & 0.611 & 0.346 & 0.000 \\
\hline Probit test (1\% VaR) & 0.000 & 0.000 & 0.914 & 0.135 \\
\hline \multicolumn{5}{|c|}{ Panel B: Weighted by Absolute Coverage Error } \\
\hline DQ test ( $5 \% \mathrm{VaR})$ & 0.191 & 0.514 & 0.381 & 0.047 \\
\hline DQ test $(1 \%$ VaR) & 0.242 & 0.054 & 0.171 & 0.281 \\
\hline Probit test (5\% VaR) & 0.085 & 0.750 & 0.726 & 0.113 \\
\hline Probit test ( $1 \%$ VaR) & 0.021 & 0.048 & 0.813 & 0.236 \\
\hline \multicolumn{5}{|c|}{ Panel C1: Weighted Asymmetrically Underprediction > Overprediction } \\
\hline DQ test $(5 \% \mathrm{VaR})$ & 0.050 & 0.514 & 0.329 & 0.280 \\
\hline DQ test $(1 \%$ VaR) & 0.243 & 0.054 & 0.143 & 0.924 \\
\hline Probit test (5\% VaR) & 0.045 & 0.750 & 0.939 & 0.672 \\
\hline Probit test ( $1 \%$ VaR) & 0.021 & 0.048 & 0.807 & 0.919 \\
\hline \multicolumn{5}{|c|}{ Panel C2: Weighted Asymmetrically Overprediction > Underprediction } \\
\hline DQ test ( $5 \% \mathrm{VaR})$ & 0.318 & 0.567 & 0.447 & 0.001 \\
\hline DQ test (1\% VaR) & 0.184 & 0.019 & 0.749 & 0.174 \\
\hline Probit test (5\% VaR) & 0.120 & 0.775 & 0.482 & 0.002 \\
\hline Probit test (1\% VaR) & 0.003 & 0.016 & 0.949 & 0.122 \\
\hline
\end{tabular}

The table reports the rejection frequency of the null hypothesis of correct conditional VaR specification, Equation (18), over $J=279$ rolling out-of-sample windows of fixed length (500 days). The first window begins on 2 September 2008 and the last window begins on 8 October 2009. DQ test is the dynamic quantile test of [12] and probit test is the probit-based variant. Panel A1 reports the rejection frequency over all windows. Panels A2 and A3 report the rejection frequencies over the first $1 / 10 J$ windows and the remaining $9 / 10 J$ windows, respectively. The last three panels report weighted rejection frequencies over all windows. Panel B weights each rejection according to the distance from the empirical conditional coverage (CC) to the nominal coverage. The empirical CC is the probit-transformed intercept, Equation (22), estimated over the J rolling out-of-sample windows. Panel C1 weights more heavily the rejections for which the empirical CC exceeds the nominal coverage (absolute distance) than the rejections for which the empirical CC is below the nominal coverage (squared distance). Panel C2 weights more heavily the rejections for which the empirical CC is below the nominal coverage (absolute distance) than the rejections for which the empirical CC exceeds the nominal coverage (squared distance). 
As formalized above, the rejection rates reported in Panel A assign equal weights to all the backtesting windows, $w_{j} \equiv 1 / J, j=1, \ldots, J$, irrespective of the distance between the empirical conditional coverage and the nominal coverage, or coverage error $\widehat{\alpha}_{j}-\alpha_{j}$. However, the economic loss function of a risk manager may assign different importance to different rejections depending on the magnitude and indeed the sign of the coverage error. Panels $B$ and $C$ add further insights by taking the magnitude and sign of the coverage error into account. Thus, Panel B summarizes the dynamic conditional coverage backtesting by weighting (or penalizing) each rejection according to the magnitude of the coverage error, i.e. $w_{j} \equiv\left|\widehat{\alpha}_{j}-\alpha_{j}\right|$ for $j=1, \ldots, J$, and the weights are standardized to add to unity.

Finally, the weighting of the rejections in Panels C1 and C2 takes also into account the sign of the error. Panel $\mathrm{C} 1$ presumes that the risk manager is more concerned about tail risk underprediction (uncovered losses concern) than overprediction (investment opportunity costs concern); thus, the penalty is larger $\left|\widehat{\alpha}_{j}-\alpha_{j}\right|, j=1, \ldots, J_{1}$ for underpredictions and smaller at $\left(\widehat{\alpha}_{j}-\alpha_{j}\right)^{2}$, $j=1, \ldots, J_{2}$ for overpredictions $\left(J=J_{1}+J_{2}\right)$. For completeness, Panel C2 reverses the direction of the asymmetry (i.e., overpredictions are penalized more heavily than underpredictions) which may be more representative of the loss function of the regulator. The evidence in Panels B and C confirms the differences between the bivariate and ex post overnight approaches with respect to the accuracy of $5 \%$ and $1 \%$ VaR forecasts. The bivariate approach outperfoms the ex post overnight approach for the Russell 2000 index; the only exception is the probit test for the 1\% VaR. In contrast, for the S\&P 500 index the results of the DQ and probit tests endorse the ex post overnight approach, especially so if the loss function assigns a larger penalty to VaR overpredictions than underpredictions.

Figure 1 plots the empirical conditional coverage, $\widehat{\alpha}_{j}$ of the bivariate and ex post overnight VaR approaches. This empirical coverage is given by the probit-transformed intercept, $\alpha=\Phi\left(\beta_{0}\right)$, estimated sequentially over $J$ rolling out-of-sample windows. For the S\&P 500 index, the graphs show that the $e x$ post overnight $5 \%$ VaR forecast stubbornly underpredicts the $5 \%$-quantile while the empirical coverage of the bivariate 5\% VaR hovers around the 5\% nominal coverage. In contrast, for the Russell 2000 index the empirical conditional coverage of the ex post overnight VaR is on the whole closer to the nominal coverage than that of the bivariate 5\% VaR. The plots for the 1\% VaR confirm this contrast between the two indices.

We interpret this contrasting evidence for the two indices as relating to differences in the efficiency of price discovery at the market open for stocks with different trading volumes. The fact that the bivariate approach excels for Russell 2000 may indicate that the opening quote for this small cap index does not reflect the information released during non-trading hours. For S\&P 500, the opening price conveys the information accumulated during non-trading hours more efficiently despite the fact that not all stocks open for trading immediately at 9:30 am, inducing the price staleness and news spillover effects discussed above. Barclay and Hendershott [13] show that for Nasdaq stocks, opening prices are more efficient for larger-volume stocks and, importantly, a critical trading volume threshold is required to shift price discovery from the trading day to the pre-open. This effectively implies that the opening price conveys more information for the most heavily-traded stocks. Our contrasting results on the relative merit of the bivariate and ex post overnight VaR approaches for the two indices are aligned with the insights in Barclay and Hendershott [13]. For small-cap (Russell 2000) stocks which display smaller trading volumes the opening price (and hence, the observed overnight return from previous close to open) is less informative, making the bivariate VaR forecasts formed at the close of day $t-1$ more accurate. There is evidence that overnight information is disseminated more efficiently on Nasdaq compared to the NYSE due to differences in the opening mechanisms of the exchanges (see e.g., Masulis and Shivakumar [9]; Greene and Watts [50]. Although Russell 2000 contains relatively more stocks listed on Nasdaq than S\&P 500 ( $60 \%$ vs. $20 \%$, respectively), the ex post previous-close-to-open return has less information content for setting day-ahead VaR equity trading limits for Russell 2000 than for S\&P 500. Overall, we interpret the evidence in our study as suggesting that the former trading volume effect is stronger than the effect of the trading platform. 
Panel A: Russell 2000 index
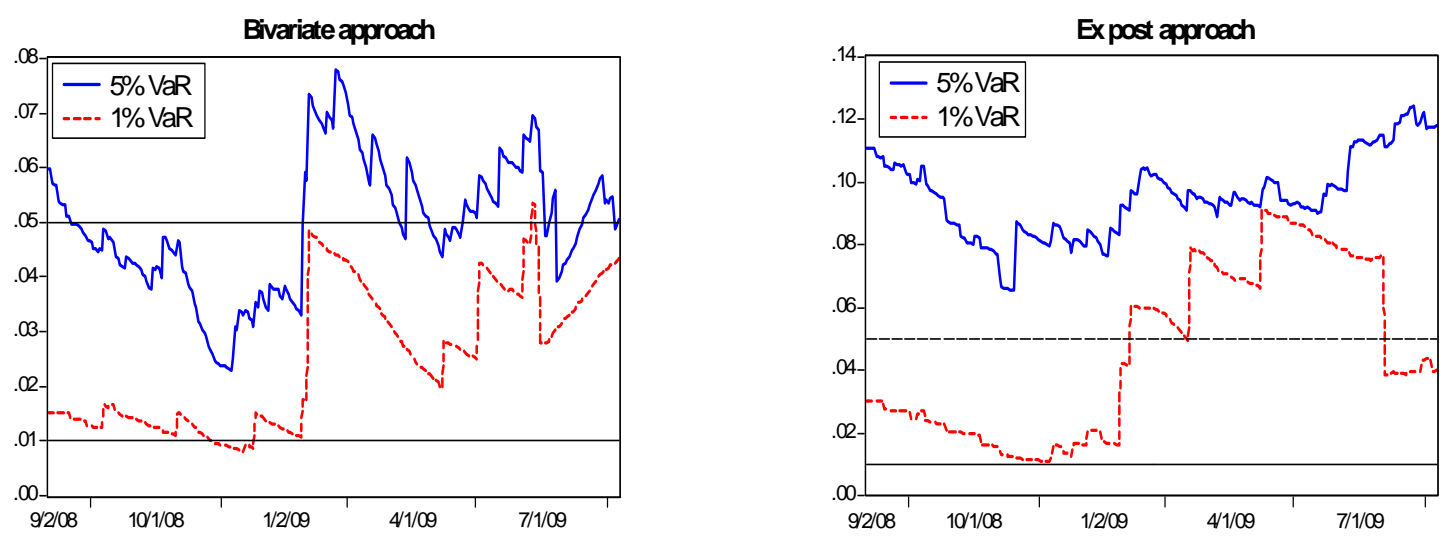

Panel B: S\&P 500 index
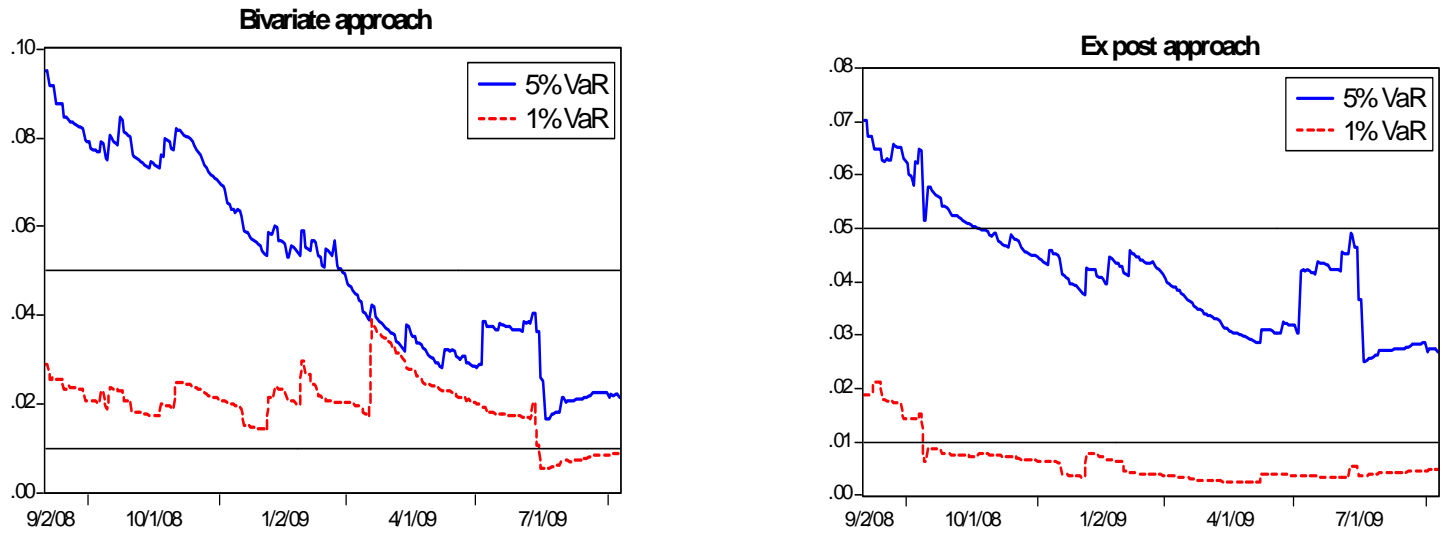

Figure 1. Empirical conditional coverage. The graphs plot the empirical conditional coverage of the bivariate VaR and ex post overnight VaR forecasting approaches described in Sections 2.2 and 2.3, respectively. The empirical conditional coverage is obtained as the probit-transformed intercept, Equation (22), estimated over 279 rolling out-of-sample (500-day) windows. The top and bottom horizontal lines denote the $5 \%$ and $1 \%$ nominal coverage, respectively, of the VaR measure. Solid (blue) line corresponds to the empirical conditional coverage at $5 \%$ and dotted (red) line corresponds to the empirical conditional coverage at $1 \%$.

\section{Conclusions}

A task faced daily by risk managers is to establish forward-looking mark-to-market loss limits for individual trading desks. Value-at-Risk $(\mathrm{VaR})$ has become a standard risk control tool.

This paper has introduced a novel VaR model that predicts the risk measure at market open and, hence, fully exploits the information released to financial markets overnight. Theoretically, this VaR measure should be more informative as it uses an expanded information set compared to standard $\mathrm{VaR}$ measures that use information up to the previous day market close. To empirically assess this hypothesis, we have compared VaR forecasts obtained from this ex post approach against VaR forecasts from a model that uses a reduced information set. The latter model uses predictions of the overnight return and the covariance between the daytime and overnight return to compute next day's VaR. The empirical comparison between these models has allowed us to shed light on the existence and importance of price staleness and news spillover. More specifically, we have explored through forecasts of the VaR measure whether the opening price fully reflects available information at market open or, instead, there is a period during which news feeds into market prices. 
Our empirical illustration reveals that conditioning the forecasts at the previous-day close and paying separate modeling efforts to the overnight and daytime segments of the day appears beneficial for describing the tail behavior of the low-cap Russell portfolio. The covariance term also adds forecast accuracy to the day-ahead VaR measure. More specifically, for the low-cap Russell 2000 index waiting until the market opens in order to construct the day-ahead VaR forecast-i.e., extending the information set to include the ex post overnight return-produces less accurate downside risk forecasts than those obtained from the bivariate modeling approach. For the large-cap S\&P 500 index, in sharp contrast, the ex post overnight modeling approach produces the most effective VaR limits. The contrasting results for the two indices may relate to the different levels of trading volume of the constituent stocks. It has been shown in previous research that price discovery at the market open is more efficient for high-volume stocks. Therefore, the large cap constituents of the S\&P 500 index may convey all relevant overnight information in their opening prices. In this case, it is worthwhile for the risk manager to generate the day-ahead VaR forecasts at the market open conditional on an extended information set that includes the close-to-open return.

This study can be extended in several dimensions. For example, we can consider subsets of individual stocks with different market capitalization and compare the performance of the two competing VaR forecasting models as a function of market capitalization. Another interesting avenue for further research is to analyze VaR forecasts for assets traded in the foreign exchange market. This market is characterized by continuous trading activity, hence, the comparison between small and large stocks and the role of the ex-ante covariance between daytime and overnight returns in predicting one-day-ahead VaR can reveal different insights in these markets.

Author Contributions: Ana-Maria Fuertes and Jose Olmo have contributed jointly and indistinctively to all of the different sections of the paper.

Conflicts of Interest: The authors declare no conflict of interest. The founding sponsors had no role in the design of the study; in the collection, analyses, or interpretation of data; in the writing of the manuscript, and in the decision to publish the results.

\section{References}

1. George, T.J.; Hwang, C.-Y. Information flow and pricing errors: A unified approach to estimation and testing. Rev. Financ. Stud. 2001, 14, 979-1020.

2. Jones, C.; Kaul, G.; Lipson, M. Information, trading and volatility. J. Financ. Econ. 1994, 36, 127-154.

3. French, K.R.; Roll, R. Stock return variances: The arrival of information and the reaction of traders. J. Financ. Econ. 1986, 17, 5-26.

4. De Gooijer, J.G.; Diks, C.G.H.; Gatarek, L.T. Information Flows around the Globe: Predicting Opening Gaps from Overnight Foreign Stock Price Patterns; Tinbergen Institute Discussion Papers 09-107/4; Tinbergen Institute: Rotterdam, The Netherlands, 2009.

5. Ahoniemi, K.; Fuertes, A.M.; Olmo, J. Overnight news and daily equity trading risk limits. J. Financ. Econ. 2015, 13, 1-27.

6. Stoll, H.R.; Whaley, R.E. Stock market structure and volatility. Rev. Financ. Stud. 1990 , 3, 37-71.

7. Ahoniemi, K.; Lanne, M. Overnight Returns and Realized Volatility. SSRN Working Paper. Available online: http:/ / ssrn.com/abstract=1945687 (accessed on 5 September 2012).

8. Chan, K.; Chan, K.C.; Karolyi, G.A. Intraday volatility in the stock index and stock index futures market. Rev. Financ. Stud. 1991, 4, 657-684.

9. Masulis, R.W.; Shivakumar, L. Does market structure affect the immediacy of stock price responses to news? J. Financ. Quant. Anal. 2002, 37, 617-648.

10. Lin, W.-L.; Engle, R.F.; Ito, T. Do bulls and bears move across borders? International transmission of stock returns and volatility. Rev. Financ. Stud. 1994, 7, 507-538.

11. Giacomini, R.; White, H. Tests of conditional predictive ability. Econometrica 2006, 74, 1545-1578.

12. Engle, R.F.; Manganelli, S. CAViaR conditional autoregressive Value-at-Risk by regression quantiles. J. Bus. Econ. Stat. 2004, 22, 367-381. 
13. Barclay, M.J.; Hendershott, T. A comparison of trading and non-trading mechanisms for price discovery. J. Empir. Financ. 2008, 15, 839-849.

14. Hasbrouck, J. High frequency quoting: Measurement, detection and interpretation. In Proceedings of the 5th EMG-ESRC Workshop on the Microstructure of Financial Markets, London, UK, 3-4 May 2012.

15. Andersen, T.G.; Bollerslev, T.; Huang, X. A reduced form framework for modeling volatility of speculative prices based on realized variation measures. J. Econ. 2011, 160, 176-189

16. Corsi, F.; Mittnik, S.; Pigorsch, C.; Pigorsch, U. The volatility of realized volatility. Econ. Rev. 2008, $27,46-78$.

17. Thomakos, D.D.; Wang, T. Realized volatility in the futures markets. J. Empir. Financ. 2003, 10, 321-353.

18. Andersen, T.G.; Bollerslev, T.; Diebold, F.X.; Ebens, H. The distribution of realized stock return volatility. J. Financ. Econ. 2001, 61, 43-76.

19. Taylor, N. A note on the importance of overnight information in risk management models. J. Bank. Financ. 2007, 31, 161-180.

20. Martens, M. Measuring and forecasting S \& P 500 index-futures volatility using high-frequency data. J. Futures Mark. 2002, 22, 497-518.

21. Giot, P.; Laurent, S. Modeling daily Value-at-Risk using realized volatility and ARCH type models. J. Empir. Financ. 2004, 11, 379-398.

22. Žikĕs, F. Semiparametric Conditional Quantile Models for Financial Returns and Realized Volatility; Mimeo Imperial College London, Business School: London, UK, 2009.

23. Fuertes, A.-M.; Olmo, J. Optimally harnessing inter-day and intra-day information for daily value-at-risk prediction. Int. J. Forecast. 2013, 29, 28-42.

24. Hansen, P.R.; Lunde, A. A realized variance for the whole day based on intermittent high-frequency data. J. Financ. Econom. 2005, 3, 525-554.

25. Barndorff-Nielsen, O.E.; Shephard, N. Econometric analysis of realised volatility and its use in estimating stochastic volatility models. J. R. Stat. Soc. Ser. B 2002, 64, 253-280.

26. Corsi, F. A Simple Long Memory Model of Realized Volatility; University of Southern Switzerland: Lugano, Switzerland, 2004; mimeo.

27. Ghysels, E.; Santa-Clara, P.; Valkanov, R. The MIDAS Touch: Mixed Data Sampling Regression Models; University of North Carolina: Chapel Hill, NC, USA, 2004; mimeo.

28. Glosten, L.; Jagannathan, R.; Runkle, D. On the relation between the expected value and the volatility of the nominal excess return on stocks. J. Financ. 1993, 48, 1779-1801.

29. Engle, R.F. Dynamic conditional correlation-A simple class of multivariate GARCH models. J. Bus. Econ. Stat. 2002, 20, 339-350.

30. Aielli, G.P. Dynamic conditional correlation: On properties and estimation. J. Bus. Econ. Stat. 2013, 31, 282-299.

31. Wu, L. Variance dynamics: Joint evidence from options and high-frequency returns. J. Econ. 2011, 160, 280-287.

32. Liu, C.; Maheu, J. Forecasting realized volatility: A bayesian model-averaging approach. J. Appl. Econ. 2009, 24, 709-733.

33. Fuertes, A.-M.; Izzeldin, M.; Kalotychou, E. On forecasting daily stock volatility: The role of intraday information and market conditions. Int. J. Forecast. 2009, 25, 259-281.

34. Basel Committee on Banking Supervision. Supervisory Framework for the Use of "Backtesting" in Conjunction with the Internal Models Approach to Market Risk Capital Requirements; Bank for International Settlements: Basel, Switzerland, 1996.

35. Kuester, K.; Mittnik, S.; Paolella, M.S. Value-at-Risk prediction: A comparison of alternative strategies. J. Financ. Econ. 2006, 4, 53-89.

36. Angelidis, T.; Degiannakis, S. Econometric modeling of Value-at-Risk. In New Econometric Modeling Research; Toggins, W.N., Ed.; Nova Science Publishers Inc.: New York, NY, USA, 2008.

37. Giacomini, R.; Komunjer, I. Evaluation and combination of conditional quantile forecasts. J. Bus. Econ. Stat. 2005, 23, 416-431.

38. Clements, M.P.; Galvão, A.B.; Kim, J.H. Quantile forecasts of daily exchange returns from forecasts of realized volatility. J. Empir. Financ. 2008, 15, 729-750.

39. Brownlees, C.T.; Gallo, G.M. Comparison of volatility measures: A risk management perspective. J. Financ. Econ. 2010, 8, 29-56. 
40. Diebold, F.X.; Mariano, R.S. Comparing predictive accuracy. J. Bus. Econ. Stat. 1995, 13, 253-263.

41. West, K.D. Asymptotic inference about predictive ability. Econometrica 1996, 64, 1067-1084.

42. West, K.D.; McCracken, M.W. Regression-based tests of predictive ability. Int. Econ. Rev. 1998, 39, 817-840.

43. Newey, W.K.; West, K.D. Hypothesis testing with efficient methods of moment estimation. Int. Econ. Rev. 1987, 28, 777-787.

44. Christoffersen, P.; Hahn, J.; Inoue, A. Testing and comparing Value-at-Risk measures. J. Empir. Financ. 2001, 8, 325-352.

45. Koenker, R.; Xiao, Z. Quantile autoregression. J. Am. Stat. Assoc. 2006, 101, 980-990.

46. Candelon, B.; Hurlin, C.; Colletaz, G.; Tokpavi, S. Backtesting Value-at-Risk: A GMM duration-based test. J. Financ. Econ. 2011, 9, 314-343.

47. Berkowitz, J.; Christoffersen, P.; Pelletier, D. Evaluating Value-at-Risk models with desk-level data. Manag. Sci. 2011, 57, 2213-2227.

48. Dumitrescu, E.I.; Hurlin, C.; Pham, V. Backtesting Value-at-Risk: From dynamic quantile to dynamic binary tests. Finance 2012, 33, 112.

49. Bandi, F.M.; Russell, J.R. Microstructure noise, realized variance and optimal sampling. Rev. Econ. Stud. 2008, 75, 339-369.

50. Greene, J.T.; Watts, S.G. Price discovery on the NYSE and the Nasdaq: The case of overnight and daytime news releases. Financ. Manag. 1996, 25, 19-42.

(C) 2016 by the authors; licensee MDPI, Basel, Switzerland. This article is an open access article distributed under the terms and conditions of the Creative Commons Attribution (CC-BY) license (http://creativecommons.org/licenses/by/4.0/). 